Outros Tempos, vol. 18, n. 31, 2021, p. 233-248. ISSN: 1808-8031

\title{
DOI: http://dx.doi.org/10.18817/ot.v18i31.830
}

EXILADOS DO SERTÃO: migração cearense na seca de $1877^{1}$

THE EXILED OF THE “SERTÃO”: migration in Ceará during the 1877 drought

EXILIADOS DEL “SERTÃO”: migración del Ceará en la sequía de 1877

JANILLE CAMPOS MAIA Doutoranda em história das ciências e da saúde / Fundação Oswaldo Cruz Rio de janeiro, Rio de Janeiro, Brasil. camposnile@gmail.com

\begin{abstract}
Resumo: O cerne deste artigo é compreender a dinâmica migratória ocorrida durante a seca de 1877 no interior da província do Ceará. Para tanto, serão utilizadas fontes oficiais como relatórios de presidente da província, além de informações compiladas em publicações semanais no jornal local $O$ cearense. Entendendo que o contexto social antes e depois de uma seca são reveladores, pretende-se considerar toda uma conjuntura histórica, e não analisar somente o desastre natural como fator isolado. A partir da utilização de um referencial teórico da História Ambiental e dos estudos sobre migração e espaço, busca-se perceber de que forma este fluxo migratório está relacionado aos desastres naturais que enfrentavam estes cearenses. Torna-se fundamental, portanto, analisar a tentativa de direcionamento dessas migrações, uma vez que as indicações do Governo Provincial guiavam o deslocamento desses retirantes para a capital cearense.
\end{abstract}

Palavras-chave: Seca. Sertão. Ceará.

Abstract: The objective of this article is to understand the migratory dynamics that occurred during the 1877 drought in the countryside of the Ceara province. To this end, official sources will be used, such as reports from the provincial president, in addition to information compiled in weekly publications in the local newspaper $O$ Cearense. Understanding that the social context before and after a drought are revealing, we intend to consider the historical conjuncture as a whole instead of analyzing the natural disaster as an isolated factor. Using a theoretical framework of Environmental History and studies on migration and space, we seek to understand how this migratory flow is related to the natural disasters faced by the Ceará peoples. It is essential, therefore, to analyze the attempt to direct these migrations, as the recommendations from the Provincial Government guided the displacement of these migrants to the capital of Ceará.

Keywords: Drought. Backland. Ceará.

Resumen: El núcleo de este artículo es comprender la dinámica migratoria ocurrida durante la sequía de 1877 en el interior de la provincia de Ceará. Para ello se utilizarán fuentes oficiales, como informes del presidente provincial, además de información recopilada en publicaciones semanales del diario local $O$ Cearense. Entendiendo que el contexto social antes y después de una sequía es revelador, se pretende considerar toda una situación histórica, y no analizar solo el desastre natural como un factor aislado. A partir del uso de un marco teórico de Historia Ambiental y estudios sobre migración y espacio, buscamos comprender cómo este flujo migratorio se relaciona con los desastres naturales que enfrentan estos pobladores cearenses. Es fundamental, por tanto, analizar el intento de focalizar estas migraciones, ya que los indicios del Gobierno Provincial orientaron el desplazamiento de estos migrantes hacia la capital cearense.

Palabras Clave: Sequía. Interior. Ceará.

\footnotetext{
${ }^{1}$ Artigo submetido à avaliação em agosto de 2020 e aprovado para publicação em dezembro de 2020.
} 
Outros Tempos, vol. 18, n. 31, 2021, p. 233-248. ISSN: 1808-8031

\section{A seca de 1877}

Um condicionante ambiental fundamental na análise da conjuntura política cearense é a seca. Este fenômeno natural é definido por Mike Davis ${ }^{2}$ como uma articulação entre estiagem e vulnerabilidade social, onde o volume de chuvas e a maneira como determinada sociedade organiza sua agricultura revelam o impacto da ausência de precipitação. Para o autor, a seca pode atingir diferentes níveis: a meteorológica é caracterizada por uma diminuição na precipitação normal durante um determinado período de tempo; a hidrológica corresponde ao momento posterior ao esvaziamento de rios e lagos, onde há a deficiência de água subterrânea. Davis afirma que este último momento representa a história social, pois é quando se percebe as políticas públicas e investimentos que foram voltados para amenizar o impacto do fenômeno meteorológico.

De maneira semelhante, Enrique Florescano $^{3}$ define a seca não apenas pela escassez de água, mas a partir de como este acontecimento natural é capaz de desestruturar determinadas sociedades. Ao compreender as causas e ação da estiagem, deve haver a preparação para enfrentamento do fenômeno climático, e a vulnerabilidade diante da chegada de uma catástrofe ambiental indica as fragilidades naturais e sociais de determinado local. Neste caso, é importante salientar que compreendo a vulnerabilidade embasada na leitura de Henri Acselrad ${ }^{4}$, em que a vulnerabilidade é socialmente construída e deve ser considerada em relação à exposição ao risco e à capacidade de adaptação, assim como a propensão de prever, enfrentar ou sofrer as consequências de algum tipo de perigo ambiental. Dessa maneira, torna-se fundamental identificar as vulnerabilidades sociais decorrentes das constantes crises climáticas que afetaram o Ceará ao destruir lavouras, rebanhos e ao condicionar o deslocamento destes indivíduos que habitavam as localidades mais atingidas em busca de comida e socorros públicos.

A seca de 1877 foi considerada um marco para a história regional nordestina e foi utilizada como argumento para diferenciação regional e consequente criação de um imaginário tipicamente nordestino. Há diversos motivos que foram estabelecidos na historiografia sobre as secas para que isto tenha ocorrido, dentre os quais podemos citar a

\footnotetext{
2 DAVIS, Mike. Holocaustos coloniais: clima, fome e imperialismo na formação do terceiro mundo. Rio de Janeiro: Record, 2002.

${ }^{3}$ FLORESCANO, Enrique. Breve historia de la sequía em Mexico. Mexico: Editora Conaculta, 2000.

${ }^{4}$ ACSELRAD, Henri. Vulnerabilidade ambiental, processos e relações. In: ENCONTRO NACIONAL DE PRODUTORES E USUÁRIOS DE INFORMAÇÕES SOCIAIS, ECONÔMICAS E TERRITORIAIS, 2., 2006, Rio de Janeiro. Anais [...]. Rio de Janeiro: FIBGE, 2006.
} 
Outros Tempos, vol. 18, n. 31, 2021, p. 233-248. ISSN: 1808-8031

desestruturação de uma economia do litoral, a precarização da assistência pública aos necessitados, a falta de distribuição de socorros no sertão, entre outros tantos fatores.

A seca agiu não apenas como uma calamidade natural, mas passou a ser um marco no pensamento cearense que condicionou o progresso da província à escassez de recursos naturais ${ }^{5}$. Segundo Evaldo Cabral de Mello ${ }^{6}$, os anos 1870 foram fundamentais na história regional do Nordeste porque foi justamente neste contexto que as diferenciações regionais passaram a ser caracterizadas e, na maior parte dos casos, foi através de denúncias de centralização dos recursos que alertavam para uma situação de desigualdade das províncias do Norte. Na tentativa de amenizar as desvantagens, as lideranças locais viram na estiagem um caminho para a conquista de financiamento para o desenvolvimento da região. Ao se tornar um assunto oficial, as elites cearenses fizeram da seca um meio burocrático para a administração de recursos por determinados grupos políticos e este conjunto de fatores corrobora para a diferenciação territorial entre Norte e Sul.

Durval Muniz de Albuquerque Junior ${ }^{7}$ retoma as origens históricas da formação deste "discurso da seca", entendendo de que forma a mesma foi utilizada por uma elite nordestina. Para Albuquerque Junior, os recorrentes casos de seca não foram suficientes para que as elites tentassem transformá-la em um problema nacional. A virada estratégica ocorre em 1877 porque, segundo o autor, o Norte passava por uma grave crise econômica em decorrência da queda do preço do açúcar e algodão, além do envio de escravos para o Sul. A perda de visibilidade nacional acentua o fenômeno climático e gera incertezas sobre o processo de recuperação econômica. Em meio ao caos ocasionado pela migração em massa para o litoral e pela desestruturação do comércio local, utilizar a seca como problema foi o caminho encontrado pela elite e governantes locais para aumento do auxílio oriundo do governo imperial. Embora tenha dizimado menos a população cearense do que a seca de 1825, o cenário de 1877 é alterado porque atingiu os grandes proprietários:

\footnotetext{
Enquanto a seca foi problema para o mundo dos despossuídos, ela era uma senhora desconhecida, não merecia mais que breves notas de rodapés de jornais, mas quando chega ao mundo dos proprietários, ela não só é percebida, como é transformada no "cavalo de batalha" de uma elite necessitada de argumentos fortes, para continuar exigindo o seu quinhão, na partilha dos benefícios econômicos e dos postos políticos em âmbito nacional ${ }^{8}$.
}

\footnotetext{
${ }^{5}$ MELLO, Evaldo Cabral de. O norte agrário e o império: 1871-1889. São Paulo: Topbooks, 1999.

${ }^{6}$ Ibid.

7 ALBUQUERQUE JUNIOR, Durval Muniz de. O engenho anti moderno: a invenção do Nordeste e outras artes. 1994. Tese (Doutorado em História) - Universidade Estadual de Campinas, Campinas, 1994.

${ }^{8}$ Id. Palavras que calcinam, palavras que dominam: a invenção da seca do Nordeste. Revista Brasileira de História, São Paulo, v. 28, p. 111-120, 1995.
} 
Outros Tempos, vol. 18, n. 31, 2021, p. 233-248. ISSN: 1808-8031

Transformar a seca em um entrave ao desenvolvimento econômico tornou-se crucial a partir do momento em que a catástrofe natural atingiu uma elite econômica cearense que já se encontrava em crise devido à queda do preço do algodão. Enquanto a pecuária adentrava o sertão e perdia o protagonismo econômico, a elite econômica em ascensão no Ceará, voltada para a plantação de algodão, ocupava serras e litoral no século XIX ${ }^{9}$. As diferentes elites econômicas ocuparam momentos concomitantes, e espaços distintos. Estes espaços cearenses precisavam ser bem delimitados para que se entendesse o funcionamento da estiagem. Para entender o processo de surgimento da ideia de região no Nordeste é preciso, portanto, remontar às crises ocasionadas pelo mercado externo e como as práticas discursivas desempenharam papel decisivo na construção da imagem da seca como problema.

Pensando igualmente na questão regional nordestina e no uso da seca como ferramenta de manutenção de poder, Frederico de Castro Neves propõe a ideia de que o Nordeste se constrói a partir do estabelecimento de uma memória regional dominante:

\begin{abstract}
A memória regional dominante, memória do espaço que se convencionou chamar Nordeste, não é apenas naturalização da região; é igualmente, tentativa de naturalizar as lutas em torno do sentido de 'regional' (de pertencimento a um espaço social delimitado política e administrativamente) que os grupos e as classes formulam para si e para a sociedade. Disseminando-se, a memória regional anula as experiências destas lutas e naturaliza o passado a partir de certos $\operatorname{marcos}{ }^{10}$.
\end{abstract}

Para Neves, esses marcos podem ser identificados a partir de três elementos: 1) relação da natureza e sociedade, através da ideia da seca como obstáculo natural ao desenvolvimento; 2) a invenção do emergencialismo, onde há a disciplinarização do homem pobre do campo por uma pedagogia do trabalho; 3) por fim, a desagregação social e desmantelamento institucional, que se desenvolve no modelo paternalista ao mesmo tempo em que se baseia nos princípios do liberalismo econômico e político, e podem ser percebidas através do atraso que se manifesta em tempos de seca, com ações de saques. $\mathrm{O}$ autor acredita que a memória regional dominante "delimita os campos de atuação política"11 e é preciso estar atento aos momentos de estiagem porque neles é que se "renovam compromissos, articulam-se alianças, reivindicam-se verbas e programas especiais, rearticulando as redes de dominação no semi-árido"12.

\footnotetext{
${ }^{9}$ MAIA, Janille Campos. Exilados da fome: seca e migração no Ceará oitocentista. 2015. Dissertação (Mestrado em Ciências Sociais em Desenvolvimento, Agricultura e Sociedade) - Universidade Federal Rural do Rio de Janeiro, Seropédica: CPDA, UFRRJ, 2015.

${ }^{10}$ NEVES, Frederico de Castro. A memória do espaço e o espaço da memória: a seca na construção imaginária do Nordeste. 1992. Dissertação (Mestrado em Sociologia) - Universidade Federal do Ceará, Fortaleza, 1992.

${ }^{11}$ Ibid., p. 191.

12 Ibid., p. 53.
} 
Outros Tempos, vol. 18, n. 31, 2021, p. 233-248. ISSN: 1808-8031

No Ceará, os efeitos da seca já eram evidenciados nos relatórios oficiais em meados de 1877 e a ausência de chuvas ocorria justamente no período em que a província costumava ter os registros pluviométricos mais elevados. O tom exacerbado presente nos relatórios do presidente da província revela o jogo político que se abria nas disputas nacionais entre Norte e Sul.

Assim, entendemos aqui que a seca influenciou todo um conjunto de organização socioeconômica onde estes indivíduos estavam inseridos e onde o controle sobre a natureza permitiu que determinados grupos tomassem decisões sobre o manejo de água e comida, assim como angariassem poder no cenário nacional. Este poder nas relações sociais, que permitiu à parcela dominante controlar os recursos naturais, leva-nos a entender a seca como um fenômeno climático que produziu impactos diretos na vida da população do sertão, uma vez que em períodos onde o regime de chuvas era baixo, havia a necessidade de reorganização da população e do controle dos espaços.

\section{Os exilados do sertão: migração interna cearense}

A definição de sertão como lugar desocupado e deserto era comum no imaginário do século XIX. Geralmente associado à ideia de espaço a ser conquistado, conhecido e delimitado, algumas expedições científicas foram enviadas a estas localidades para explorar sua vegetação, fauna e clima. No Ceará, o sertão foi estudado por duas principais expedições externas - Comissão Científica de Exploração e Comissão da Carta Geral do Império ${ }^{13}$, além de pesquisadores locais que produziram relatórios com dados populacionais e físicos sobre o Ceará.

Para o presente artigo, ser-me-á cara a definição de sertão vinculada no Ensaio Estatístico da Província do Ceará de Thomaz Pompeo de Souza Brasil ${ }^{14}$, no qual sertão significa todo espaço oposto ao litoral, além de ser formado por terrenos secos e pedregosos. Dentro deste ambiente descrito e estudado por um arsenal científico do século XIX, importa

\footnotetext{
${ }^{13}$ A Comissão da Carta Geral do Império foi criada em 1862 com o intuito de realizar observações astronômicas e meteorológicas que fossem pautadas pelo conhecimento científico. No Ceará, a comissão liderada pelo engenheiro Henrique Rohan chega em 1877 para estudar e entender a seca nas províncias do Norte. A Comissão Científica de Exploração, por sua vez, foi organizada pelo Instituto Histórico e Geográfico Brasileiro em 1856 com objetivo de realizar pesquisas botânicas, astronômicas, geográficas e etnográficas do Ceará. Para maiores informações, ver KURY, Lorelai (org.). Comissão Científica do Império. Rio de Janeiro: Andrea Jakobsson, 2009.

14 BRASIL, Thomas Pompeo de Sousa. Ensaio estatístico da Província do Ceará. Tomo I. Ed. Fac-similar. Fortaleza: Fundação Waldemar Alcântara, 1997.
} 
Outros Tempos, vol. 18, n. 31, 2021, p. 233-248. ISSN: 1808-8031

perceber de que maneira a população que habitava essas localidades foi atingida a partir da chegada da seca de 1877.

Os relatórios evidenciavam que o sertão apresentava um cenário estável em períodos de chuvas regulares e sem grandes problemas relacionados à falta de alimentos. Essa condição era alterada a partir da ausência de chuvas, onde o sertanejo caía em um regime de subalimentação. Segundo Josué de Castro $^{15}$, com a chegada da seca, a alimentação do sertanejo se reduzia a milho, feijão e farinha. Com a permanência da estiagem, havia a mudança do regime alimentar do sertão e aos sertanejos restava comer plantas resistentes ao ambiente seco, principalmente raízes.

A fome surgia durante a seca e gerava a crise alimentar nestes espaços desprovidos da atenção do poder público. Interessa-nos aqui entender de que forma o conhecimento sobre o espaço habitado pelos indivíduos do sertão interferiu no processo de organização e distribuição de socorros públicos. Afinal, apenas os condicionantes ambientais influenciaram no deslocamento destes indivíduos? Existiam socorros públicos nas localidades onde havia um maior número de migrantes?

Ao refletir sobre as políticas públicas e fornecimento de socorros públicos pelo governo da província do Ceará, percebemos que a migração foi uma das pautas utilizadas para angariar a atenção do governo imperial e em diversos momentos era colocada como estratégia para obtenção de recursos:

Também pelo lado econômico não se recommendava a emigração. [...] Todavia a
falta de meios para alimentar um tão crescido número de pessoas, e os interesses da
ordem e da saúde pública que soffriam com as grandes aglommerações, me
determinaram a facilitar a sahida para fora da província, enquanto não recebesse os
auxílios solicitados ao Governo ou não me fossem dadas outras ordens e
instruções ${ }^{16}$.

Apresentada como um atraso econômico, a emigração provocava o esvaziamento demográfico do sertão, além de causar um grande impacto na perda de mão de obra local. Por outro lado, manter os retirantes na capital representava gerar aglomerações e gastos com o fornecimento de socorros públicos.

\footnotetext{
${ }^{15}$ CASTRO, Josué de. Geografia da fome. Rio de Janeiro: Civilização Brasileira, 2011.

${ }^{16}$ Falla com que o ex.mo sr. dr. José Julio de Albuquerque Barros, presidente da provincia do Ceará, abriu a 1.a sessão da 24.a legislatura da Assembléa Provincial no dia 1 de novembro de 1878. Fortaleza, Typ. Brasileira, 1879. p. 41. Disponível em: http://brazil.crl.edu/ . Acesso em: 12 dez. 2014.
} 
Outros Tempos, vol. 18, n. 31, 2021, p. 233-248. ISSN: 1808-8031

Em seu trabalho sobre a seca de 1877 , Verónica Secreto ${ }^{17}$ detalha como a migração para fora da província era debatida pelo poder público local. Neste contexto, ainda por influência do senador Pompeu, o poder público "desautorizava os socorros diretos, a 'esmola' ou 'caridade'. Em seu lugar, propunha que os socorros deveriam ser oferecidos em forma de 'remuneração' ou salário por um trabalho realizado" ${ }^{18}$. A novidade salientada por Secreto diz respeito às mudanças na maneira pela qual a seca e o trabalho passaram a ser encarados pelas autoridades locais.

$\mathrm{O}$ envio de cearenses para fora da província representava um perigo para o desenvolvimento econômico do Ceará, assim como a concentração de migrantes nas ruas da capital. A aglomeração se configurava como uma preocupação principal nos relatórios oficiais, e, segundo o presidente da província José Júlio de Albuquerque Barros, esse contingente cresceu expressivamente ao final de 1877 e início de 1878 :

A calamidade que peza sobre o Ceará é do número d'aquellas que illudem todos os
cálculos da previsão humana, e muitas vezes tem produzido malles irreparáveis,
antes que se manifeste claramente. E que a para da secca normal, regular, benéfica,
vem a secca extraordinária, cujo princípio e termo é igualmente difícil determinar,
dependendo das causas metereológicas, incertas e variáveis, podendo uma chuva de
mais ou de menos originar uma outra, interromper ou prolongar o seu curso. Os
danos produzidos pela secca regular, que se espera de Julho a Dezembro, podem
com rasão ser impotados a imprevidências dos habitantes, e n'outra parte os lancei a
conta do deffeituoso systema de criação, e de atraso da agricultura. Mas nas actuaes
condições da província, não está nas forças do homem impedir que as grandes
seccas, acompanhadas sempre de mortíferaas pestes, produzam os maiores estragos
e soffrimentos.
Duas causas principaes concorrem para isto: a falta de depósito d'agua nos sertões e
a deficiência dos meios de transporte. É sabido que depois das hordas selvagens, são
os pastores ou os creadores os que mais soffrem com os effeitos de taes
calamidades, o gado morre mas depois de devorar a lavoura e muitas das reservas de
provisão destinadas à alimentação humana, deixando após a fome e os elementos
miasmáticos que a corrupção das matérias animaes desenvolve nos campos. Nos
sertões da província onde a criação de gado é a principal indústria, não se pode
recorrer a irrigação para obter cereaes e forragens, de que as águas se conservem na
superfície do solo, porque baixando um ou dois metros de profundidade, encontra
uma rocha salgada que as torna imprópria para a vida animal e vegetativa. D’ahi
numerosa emigração ${ }^{19}$.

A adoção de medidas para controle deste deslocamento era evidentemente acentuada nos relatórios oficiais. A migração se mostrava intensa já em 1877 e era uma preocupação constante naquele contexto político cearense. Em novembro de 1878, já havia

17 SECRETO, María Verónica. A seca de 1877-1879 no Império do Brasil: dos ensinamentos do senador Pompeu aos de André Rebouças: trabalhadores e mercado. História, Ciências, Saúde - Manguinhos, Rio de Janeiro, v. 27, n. 1, p. 33-51, jan./mar. 2020.

${ }^{18}$ Ibid., p. 44.

${ }^{19}$ Falla com que o ex.mo sr. dr. José Julio de Albuquerque Barros, presidente da provincia do Ceará, abriu a 1.a sessão da 24.a legislatura da Assembléa Provincial no dia 1 de novembro de 1878. Fortaleza, Typ. Brasileira, 1879. p. 39. 
Outros Tempos, vol. 18, n. 31, 2021, p. 233-248. ISSN: 1808-8031

mais de 200 mil migrantes vindos do sertão em busca de auxílios na capital, carente de asseio e de organização administrativa que amenizasse o impacto da seca no interior da província.

Apesar de alegar o envio de ajuda a toda província, a população do sertão seguia sofrendo com mais intensidade as consequências daquela seca devastadora. Permanecer em sua própria terra e conseguir sobreviver apesar da ausência de chuvas não parecia uma alternativa muito viável, ainda mais quando se leva em consideração um dos fatores fundamentais para a migração: a distribuição de socorros.

A Comissão de $\operatorname{socorros}^{20}$ teve importante papel por assistir os retirantes que chegavam à capital a procura de suprimentos. Segundo José Souza ${ }^{21}$, a cidade foi organizada em distritos (conhecidos como abarracamentos), que eram construídos de forma improvisada pelos próprios indigentes. Neste local eram feitas a distribuição dos socorros, em troca do trabalho dos retirantes. A disposição do espaço era realizada em separação de homens e mulheres, além de "escolas separadas para meninos e meninas, um conjunto de empregados com diferentes funções como inspetores, chefes de famílias, escrivães, chefes das olarias, enfermeiras, cozinheiros, lavanderia e serventes para as enfermarias" ${ }^{22}$. Embora houvesse lista de espera para ter direito à assistência, através destes centros de distribuição era possível considerar parte do número de indigentes que chegava do interior da Província, assim como a condição de saúde daqueles indivíduos:

Com relação aos emigrantes, que se recolhiam à Capital, regularisei os serviços necessários á sua recepção - alojamento, socorros e tratamento.

Nomeei a cidadãos prestimosos a quem incumbi especialmente da distribuição de socorros, mandando construir abarracamentos nas immediações da cidade, onde são recolhidos pelos membros das comissões domiciliárias.

Uma parte diminuta d'esses emigrantes, cedendo ao movimento migratório, que se estabeleceu para fora da província, tem se retirado para o Maranhão, Pará e Amazonas, e ultimamente para o Sul do Império, conforme resolveu o Governo Imperial.

Até o ultimo recenseamento, o número de emigrantes sahidos para norte e sul do Império orçava por 3.503, sem contar os que tem se retirado por terra, e cujo número é bastante avultado.

Para melhor direção do serviço e distribuição dos socorros devido aos emigrantes, que aqui estão permanecendo, separei-os em cinco distritos:

O $1^{\circ}$ distrito no lugar - Meirelles - a cargo do Dr. Henrique Theberge, com uma população de 4.480 representando 747 famílias em 128 barracas feitas de madeira e palha, estando outras famílias em casinhas particulares.

O $2^{\circ}$ distrito está confiado a direção do alferes Joaquim Nogueira de Hollanda Lima, e compreende os abarracamentos do Pajehu, Alto da Pimenta, São Luiz, Estrada de Mecejana e do major Thomaz, e bairro do Livramento - o qual acha-se dividido em

\footnotetext{
${ }^{20}$ A Comissão de socorros esteve vinculada às Obras Públicas durante a seca de 1877. A partir de 1909, passa a ser institucionalizada através da criação do IOCS. Para maiores informações, ver SOUZA, 2015.

${ }^{21}$ SOUSA, José Weyne Freitas. Política e seca no Ceará: um projeto de desenvolvimento para o Norte (18691905). 2009. Tese (Doutorado em História Econômica) - Universidade de São Paulo, São Paulo, 2009.

${ }^{22}$ Id. Secas e socorros públicos no Ceará: doença, pobreza e violência (1877-1932). Projeto História, São Paulo, n. 52, p. 178-219, jan./abr. 2015. p. 187.
} 
Outros Tempos, vol. 18, n. 31, 2021, p. 233-248. ISSN: 1808-8031

\begin{abstract}
dous, denominados - Alto da Pimenta e Pajehu - sendo este confiado a direção do capitão Raymundo Serafim dos Anjos Jatahy.

Todos esses abarracamentos contem uma população de 14.129 emigrantes habitando palhoças que se acham construídas.

O $3^{\circ}$ distrito com uma população arrolada de 15.700 almas foi necessários dividi-lo em dous, denominados - abarracamento de São Sebastião e Calçamento - o $1^{\circ}$ a cargo do capitão Antônio dos Santos Neves, e o $2^{\circ}$ confiado ao dr. Metton de Franca Aguiar.

O $4^{\circ}$ distrito é dirigido pelo pharmaceutico João Francisco Sampaio e demora nos lugares Tijubana e Morro do moinho, com uma população de 8.046.

O $5^{\circ}$ distrito está confiado ao tenente Felippe de Araujo Sampaio, e denomina-se Lagoa Seca, o qual contem 116 famílias de indigentes com 576 pessoas. $^{23}$
\end{abstract}

Se compararmos os locais de construção desses primeiros abarracamentos com os primeiros locais atingidos pela seca, é possível notar que os municípios de "Telha, Lavras, Tamboril, Quixeramobim, Icó, Sobral, Canindé, Cachoeira, São Bernardo, Várzea Alegre, Quixadá, São Francisco, Imperatriz, Acarape, Villa do Espirito Santo e Santa Quitéria, foram os primeiros onde a crise se accentuou" 24 , no entanto, a escolha do lugar de construção dos primeiros abarracamentos são sempre na capital e as pessoas do sertão sequer foram contempladas pela assistência pública neste primeiro momento.

Ainda em 1877, Caetano Estellita Cavalcanti Pessoa criou oficinas de trabalho e iniciou diversas obras, aproveitando a mão de obra dos migrantes. O então presidente da província, inspirado pelos ensinamentos do senador Pompeu, acreditava na necessidade do trabalho com o aproveitamento de indivíduos para que ocupasse suas mentes.

De uma maneira geral, os indigentes eram divididos em quatro classes dentro dos abarracamentos: os recém-chegados que queriam alojar-se nos abarracamentos dos subúrbios; os interessados em migrar para fora da província; os domiciliados na capital; e os abarracados no subúrbio ${ }^{25}$. Em 1878, o número de migrantes cresce vertiginosamente e o então presidente da província, José Júlio de Albuquerque Barros, apresenta um panorama desolador do Ceará, que contava então com mais de duzentos mil emigrados do interior.

Ao pensar na distribuição de socorros e no constante movimento migratório dentro da Província, o então presidente José Julio de Albuquerque Barros explica a dificuldade de envio de auxílios para o interior:

\footnotetext{
${ }^{23}$ Falla com que o ex.mo sr. dezembargador Caetano Estellita Cavalcanti Pessoa, presidente da provincia do Ceará, abriu a 2.a sessão da 23.a legislatura da respectiva Assembléa no dia 2 de julho de 1877. Fortaleza, Typ. do Pedro II, 1877. p. 37.

${ }^{24}$ Ibid., p. 39.

${ }^{25}$ Falla com que o ex.mo sr. dr. José Julio de Albuquerque Barros, presidente da provincia do Ceará, abriu a 1.a sessão da 24.a legislatura da Assembléa Provincial no dia 1 de novembro de 1878. Fortaleza, Typ. Brasileira, 1879. p. 47.
} 
Outros Tempos, vol. 18, n. 31, 2021, p. 233-248. ISSN: 1808-8031

Os danos produzidos pela secca regular, que se espera de Julho a Dezembro, podem com rasão ser impotados a imprevidências dos habitantes, e n'outra parte os lancei a conta do deffeituoso systema de criação, e de atraso da agricultura. Mas nas actuaes condições da província, não está nas forças do homem impedir que as grandes seccas, acompanhadas sempre de mortíferaas pestes, produzam os maiores estragos e soffrimentos.

Duas causas principaes concorrem para isto: a falta de depósito d'agua nos sertões e a deficiência dos meios de transporte. É sabido que depois das hordas selvagens, são os pastores ou os creadores os que mais soffrem com os effeitos de taes calamidades, o gado morre mas depois de devorar a lavoura e muitas das reservas de provisão destinadas à alimentação humana, deixando após a fome e os elementos miasmáticos que a corrupção das matérias animaes desenvolve nos campos. Nos sertões da província onde a criação de gado é a principal indústria, não se pode recorrer a irrigação para obter cereaes e forragens, de que as águas se conservem na superfície do solo, porque baixando um ou dois metros de profundidade, encontra uma rocha salgada que as torna imprópria para a vida animal e vegetativa. D'ahi numerosa emigração. ${ }^{26}$

Se a presença da seca desestabiliza o sertão, a capital é afetada pelo contingente populacional que chega diariamente. Interessa aqui mencionar a origem dessas famílias a fim de entender a dinâmica migratória da província. Ao procurar os dados referentes à migração, podemos observar o movimento de deslocamento das famílias para os abarracamentos já no ano de 1877:

Gráfico 1: Famílias de migrantes do $2^{\circ}$ Distrito por origem

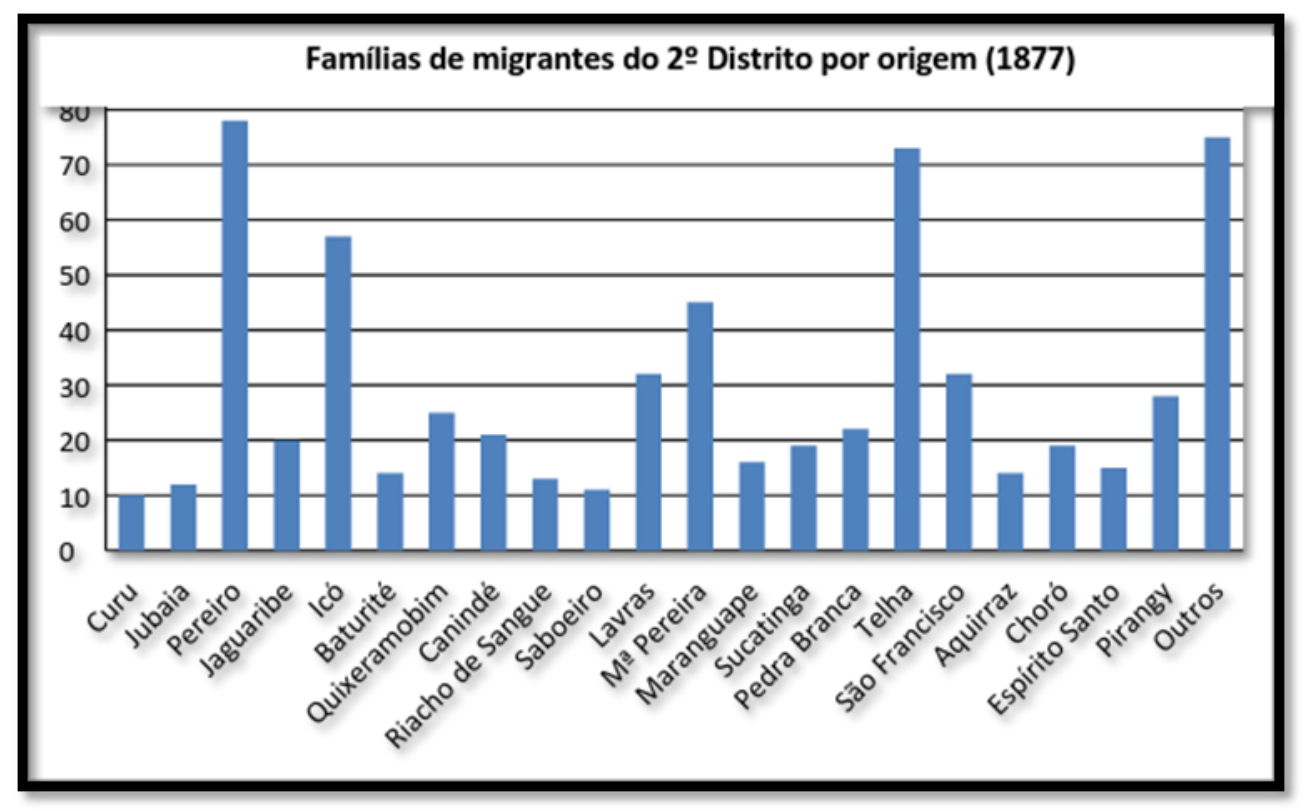

Fonte: Os dados foram coletados da seção Emigrantes do jornal $O$ Cearense, durante os meses de agosto a dezembro de 1877. A contagem era publicada semanalmente no periódico.

${ }^{26}$ Ibid., p. 39. 
Outros Tempos, vol. 18, n. 31, 2021, p. 233-248. ISSN: 1808-8031

Ao observarmos os dados, podemos notar que a chegada de retirantes se dá principalmente de algumas regiões onde a seca atingia de maneira mais intensa. No caso do abarracamento do $1^{\circ}$ distrito não foi possível obter informações detalhadas da origem dessas famílias. No entanto, ao considerarmos os dados do abarracamento do $2^{\circ}$ distrito, a cargo de Holanda Lima, percebemos que grande parte das pessoas que estão se deslocando para o litoral são provenientes de Icó, Pereiro e Telha. No $3^{\circ}$ e $4^{\circ}$ distrito, no entanto, a maioria dessas famílias são oriundas de Curu, Pereiro e São Francisco:

Gráfico 2: Famílias de migrantes do $3^{\circ}$ Distrito por origem

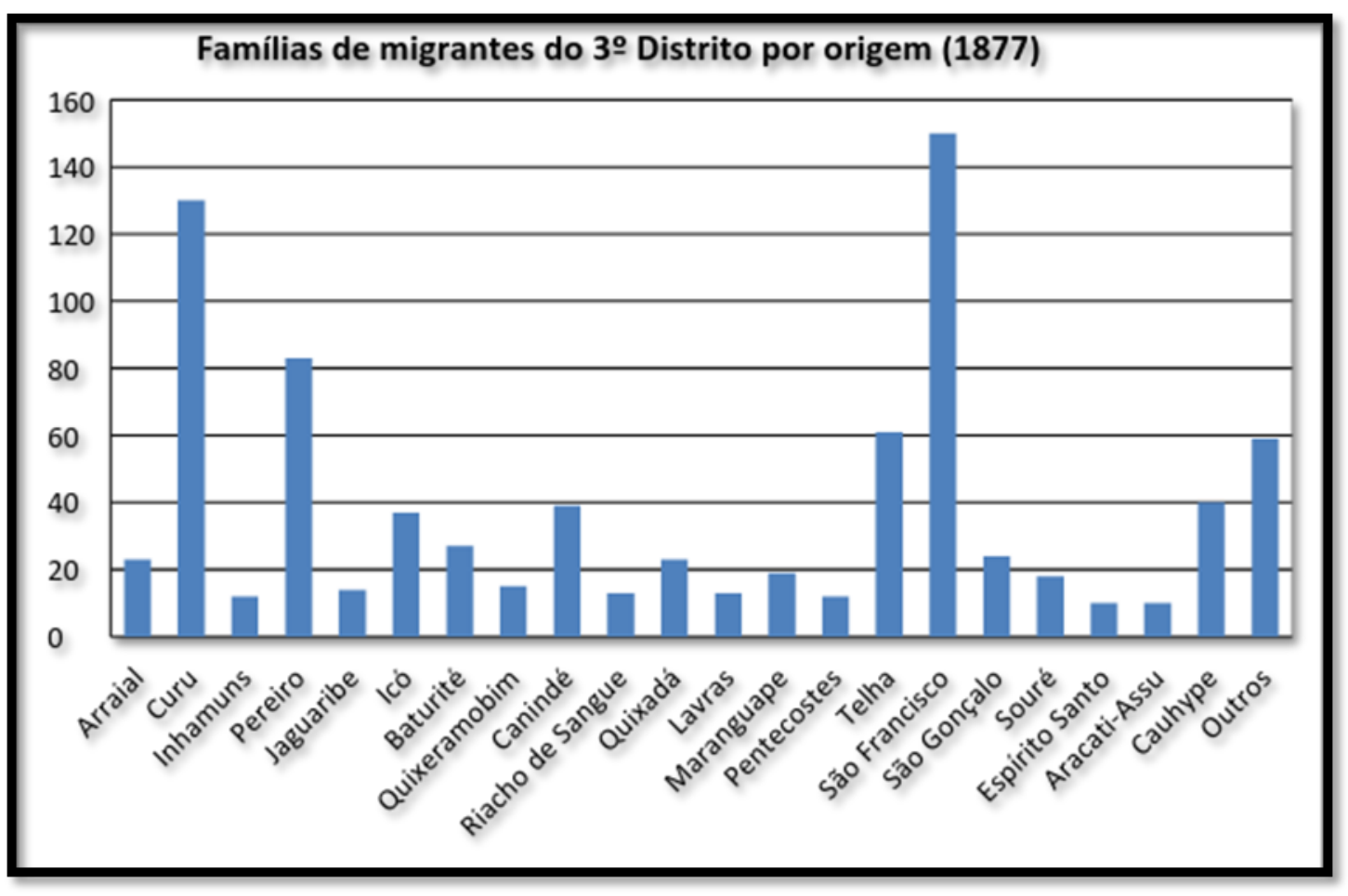

Fonte: Os dados foram coletados da seção Emigrantes do jornal $O$ Cearense, durante os meses de agosto a dezembro de 1877. A contagem era publicada semanalmente no periódico. 
Outros Tempos, vol. 18, n. 31, 2021, p. 233-248. ISSN: 1808-8031

Gráfico 3: Migrantes do $4^{\circ}$ Distrito por origem

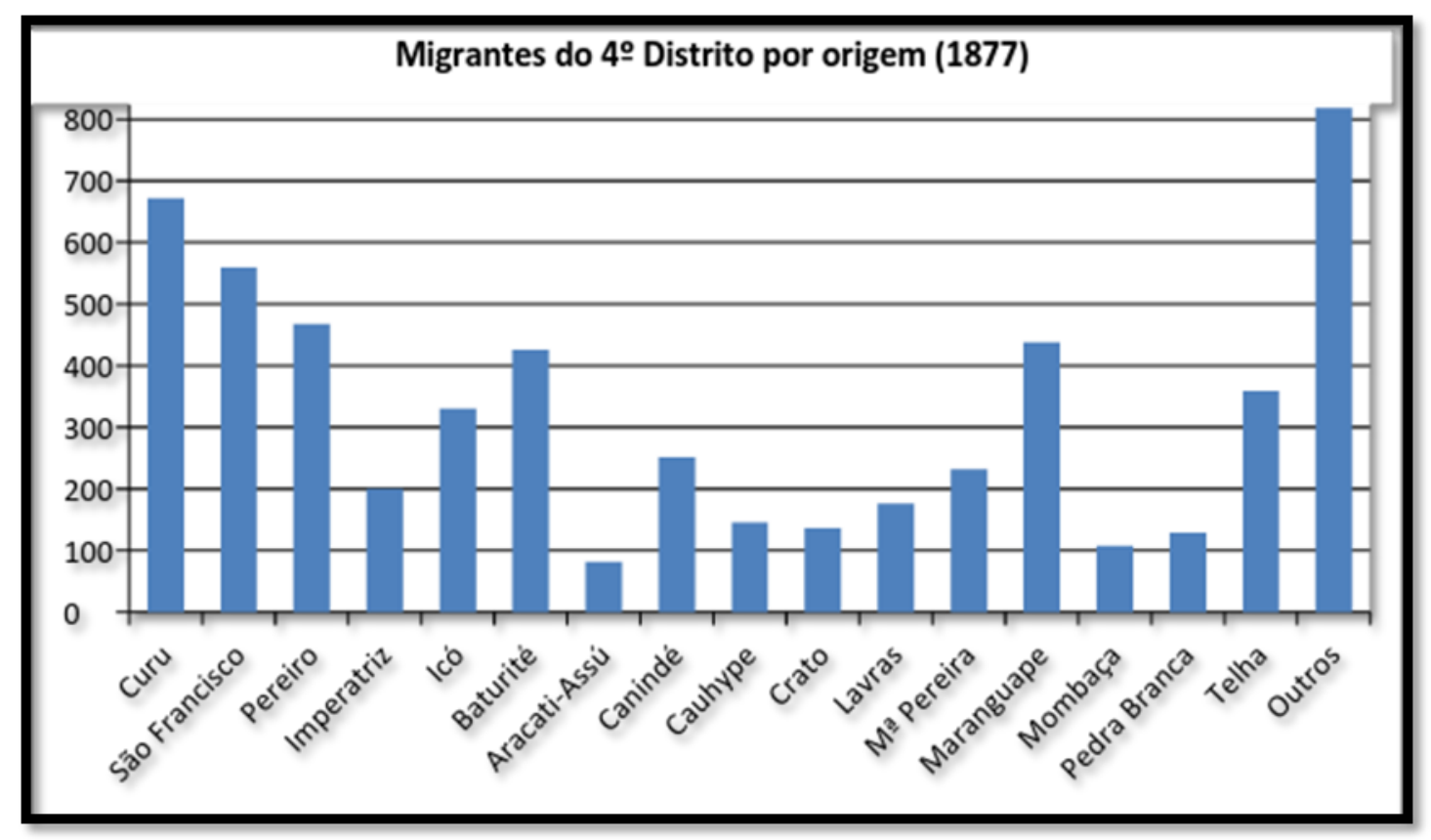

Fonte: Os dados foram coletados da seção Emigrantes do jornal $O$ Cearense, durante os meses de agosto a dezembro de 1877. A contagem era publicada semanalmente no periódico.

Se considerarmos que as regiões afetadas são interiorizadas, podemos notar que grande parte dessas famílias se deslocava em busca dos socorros distribuídos na capital. No mapa abaixo é possível visualizar as principais localidades de origem das famílias migrantes dos três centros de distribuição de socorros mencionados: 
Outros Tempos, vol. 18, n. 31, 2021, p. 233-248. ISSN: 1808-8031

Mapa 1: Principais localidades de onde as famílias eram oriundas

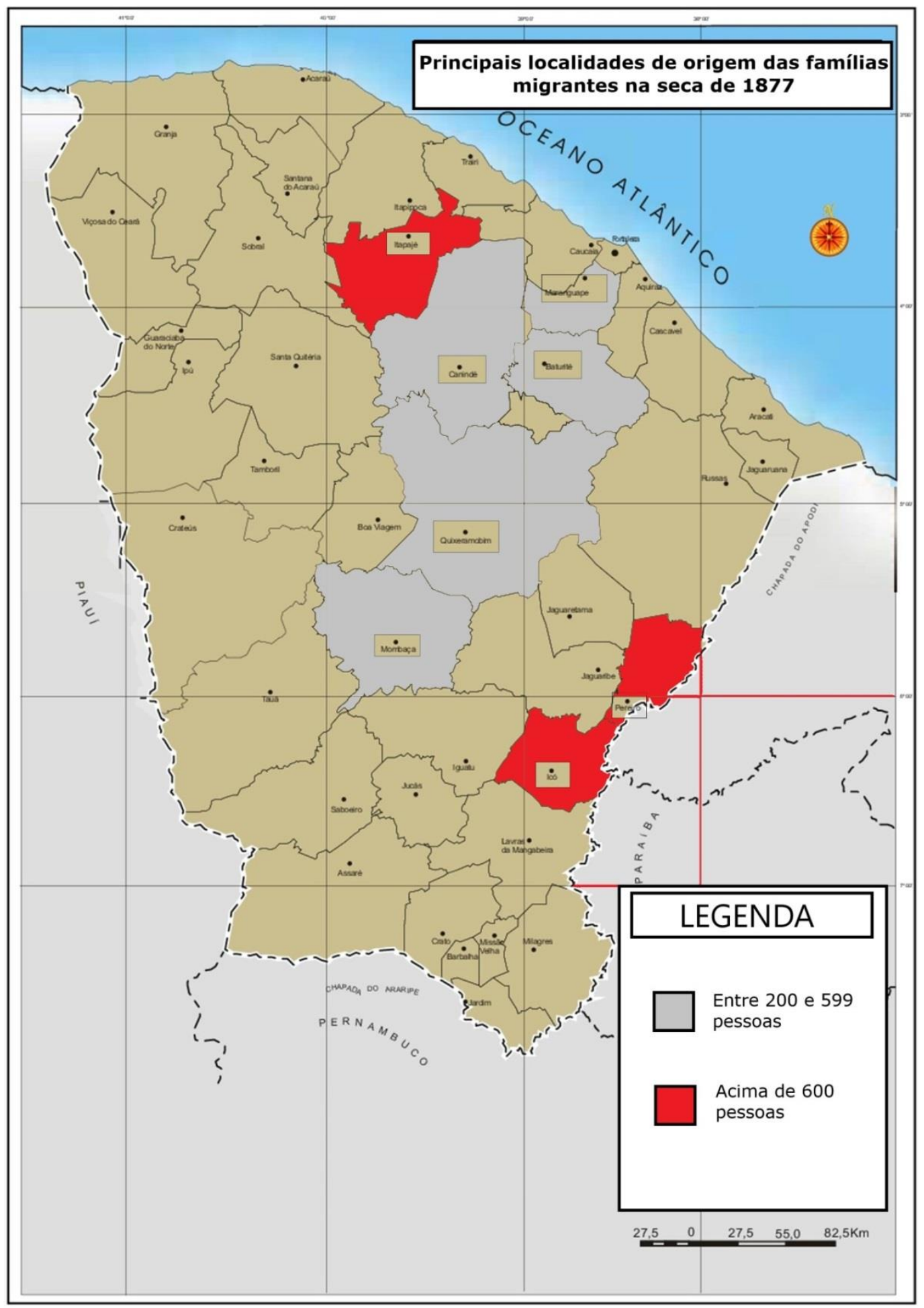

Fonte: Instituto de Pesquisa e Estratégia Econômica do Ceará. A base do mapa com a divisão políticoadministrativa foi retirada da seção Ceará em Mapas do IPECE. Os dados inseridos foram coletados a partir das publicações semanais no jornal $O$ Cearense em 1877.

Esses locais são peças-chave para entender a lógica que estava presente na migração desses cearenses. Icó, Pereiro e Telha ficavam próximos a Russas, sobre os rios 
Outros Tempos, vol. 18, n. 31, 2021, p. 233-248. ISSN: 1808-8031

Jaguaribe e Salgado. O município de Icó possuía todo o terreno na parte denominada sertão, e, segundo Thomaz Pompeu ${ }^{27}$, o terreno de Icó era todo de massapê, bem seco, porém fértil durante a estação chuvosa, onde se fazia a plantação nas margens dos rios e nos açudes e a principal atividade econômica era a criação de gados. Pereiro, por sua vez, tinha maior parte de seu terreno localizado em um extenso vale nas serras de São Cosme e São Damião e Camará. Era uma região própria para o cultivo de algodão e legumes. Telha, localidade afetada que pertencia a Icó, estava localizada sobre o rio Jaguaribe, no chamado sertão de Quixeló. De acordo com os dados do Recenseamento Geral do Império de 1872, a freguesia de Icó contava a população de cerca de 13 mil habitantes, enquanto Telha possuía por volta de 17 mil. Pereiro, por sua vez, contava com cerca de 11 mil habitantes no mesmo período.

Curu e São Francisco, outras duas regiões de onde partiam maior parte da população de retirantes, estavam localizados no município de Itapajé, na serra de Uruburetama. Curu possuía parte de seu território no sertão e na serra, com terreno bem pedregoso e fértil, onde se plantava café, cana legumes e algodão. São Francisco também tinha seu território na serra de Uruburetama, onde se plantavam legumes, mandioca, café e algodão. Pelo Recenseamento Geral do Império de 1872, as localidades possuíam cerca de 11 mil habitantes.

Os outros municípios mencionados tiveram um número inferior no que diz respeito à saída de retirantes para a capital. No entanto, este número é representativo se considerarmos a população das localidades, assim como o fato de que foram um dos primeiros locais de deslocamentos. Em 1872, Canindé possuía 11 mil habitantes, Baturité 26 mil, Maranguape 15 mil, Quixeramobim 15 mil e Mombaça cerca de 11 mil habitantes.

Essas pessoas saíam de suas terras muitas vezes direcionadas a determinados locais onde havia a assistência pública. Muito embora o poder público negasse a interferência da espacialidade dos abarracamentos na vida daquelas famílias migrantes, é evidente que a distribuição de socorros apenas nas redondezas da capital gerou um direcionamento desses retirantes.

O grande número dos que se deslocavam tornava a migração uma questão primordial na política oficial de controle sobre as secas. Por um lado, alegava-se que não havia efetivamente condições objetivas para manter tantos milhares de indivíduos durante muitos meses com a assistência do governo e, assim, a emigração se tornava praticamente inevitável. Por outro lado, a saída em massa de tantos sertanejos gerava o problema da falta de

27 BRASIL, Thomas Pompeo de Sousa. Ensaio Estatístico da Província do Ceará. Tomo II. Ed. Fac-similar (1863). Fortaleza: Fundação Waldemar Alcântara, 1997. 
Outros Tempos, vol. 18, n. 31, 2021, p. 233-248. ISSN: 1808-8031

braços para que, na normalização do regime de chuvas, a economia local pudesse contar com trabalhadores.

Cabe ressaltar aqui que a seca de 1877 e toda tentativa de angariar recursos para o Nordeste ajudou a gerar o desespero no sertão. O permanecer na província revela o projeto de transitoriedade que estava presente no imaginário daquele sertanejo, que em sua maioria visava o retorno após o fim da estiagem. O fluxo de famílias marchando em busca do alimento era um cenário desolador, ainda mais quando se considera a quantidade de retirantes que sequer conseguia alcançar seus destinos.

\section{Considerações Finais}

Interpretar as rotas migratórias como experiências significativas é um passo importante para se compreender as circunstâncias de inserção de sertanejos e outros migrantes que vivenciaram a seca de 1877. Por onde passavam, esses migrantes de diferentes procedências e variadas trajetórias encontravam-se em certos pontos de aglomeração como vilas e cidades. Em uma pluralidade de projetos migratórios, o indivíduo que vinha de Telha, Icó, São Francisco, Curu, Pereiro, dentre outras localidades, buscava muitas vezes fugir dos efeitos da seca no único local de apoio possível.

O senador Pompeu foi um dos personagens a se deter sobre a configuração espacial do Ceará. Na obra Ensaio Estatístico da Província do Cearáa ${ }^{28}$, o autor fez um levantamento dos fatores ambientais que ocasionavam a seca e de que maneira a Província do Ceará precisava ser caracterizada em sua bacia hidrográfica, flora, fauna, temperatura, população, além do que era produzido pelas atividades econômicas. A pesquisa revela que a preocupação com o domínio da natureza local caracterizava a necessidade de duas ações diferentes: para o Ceará quente e úmido do litoral e das serras; outra para o quente sertão, descrito como de solos rasos e pedregosos, além de chuvas escassas e mal distribuídas, com vegetação de caatinga.

O que se pode empreender a partir dos dados coletados e analisados é que, apesar do conhecimento travado acerca do sertão, a seca de 1877 revelou que poucos socorros públicos chegaram às localidades mais afastadas da capital. A preocupação evidente com Fortaleza em todas as narrativas apresenta não apenas o desconhecimento do interior da província, como o abandono das políticas públicas. Os socorros prestados em localidades 
Outros Tempos, vol. 18, n. 31, 2021, p. 233-248. ISSN: 1808-8031

específicas aceleram o processo migratório e concentram a população faminta em um só lugar. A distribuição de socorros intensifica a migração, que posteriormente gera o caos relatado em 1878 .

A intencionalidade das ações públicas em transformar a seca de 1877 em um grande acontecimento não pode passar despercebida. O ano de 1877 passou a ser o marco da mudança de significado para uma elite local: a estiagem representava não apenas a ausência de chuvas no sertão, mas também a tentativa de obtenção de recursos do Governo Imperial. O envio da Comissão Carta Geral do Império para análise da conjuntura ambiental cearense representava a visibilidade que conseguiram alcançar no âmbito nacional. No entanto, a seca não teve apenas consequências escabrosas para a população cearense que migrou e se concentrou na capital. Acabou atingindo grandes proprietários do litoral e a doença chegou ao palácio do governo, vitimando a esposa do presidente da província pela varíola. 